\title{
Research on the Tablet Computer Application of Preschool Children in Guangzhou City under the View of Media Literacy
}

\author{
$\mathrm{Li} \mathrm{Jie}^{1}$ \\ 1Associate Professor of Journalism and Communication \\ College of Jinan University
}

\begin{abstract}
This paper studies how preschool children use tablet and to what extent their parents' media behavior influences them by using a questionnaire on 200 preschool children and their parents together with interviews from Guangzhou to explore. The survey found that parents' media behavior and attitude to touchscreen tablets influences their children in different extent. The items children play on tablets are quite similar to their parents. Children who play tablets especially games conflict with parents more often. Finally, a solution was ventured and some strategies advanced to improve preschool children' literacy of using tablet.
\end{abstract}

Keywords: tablet computer; preschool children; parents; media literacy

\section{INTRODUCTION}

Since 2010 to now, the tablet PC storm waved by iPad greatly accelerates the process of media in children' life. Many children "use the fingers to touch the screen of tablet computer when they cannot speak and know words... When they cannot yet fully express and write in words, they can receive all kinds of information from the electronic media through sight sense, hearing sense and touch sense, and then interact with it. People have never closely contact, apply and depend on the media from the beginning like this" ${ }^{[1]}$. From the perspective of media literacy, the media application of children is related closely with family environment, especially the media contact and behavior of parents.

This research sets the preschool children in Guangzhou (refer in particular to the children in little class, middle class, big class in kindergarten and preschool class, which has the ages from 3 to 7) as the object, then research the media access and usage behavior of parents (access kinds and access contents), the interactive relationship of parents and children in application, so as to investigate the influence factors that affect children' tablet computer application, and then puts forward suggestions for tablet computer literacy cultivation of preschool children.

In order to cover all the families with different social classes and economic conditions, the research selects the 3

\author{
Chen Zixi ${ }^{2}$ \\ ${ }^{2}$ Master Graduate in Journalism and Communication \\ College of Jinan University
}

kindergartens of Guangzhou City Xiaojingling Kindergarten, South China Normal University Third Affiliated Kindergarten and Gretel Montessori Kindergarten as the survey representative with different family economic conditions and education levels. This research sends the questionnaires to the parents of 200 preschool children during January to February in 2015, receives 161 effective questionnaires, among them, male children accounts for $58 \%$, female accounts for $42 \%$; the proportion of children in 3 to 4 ages, elder than 4 ages to 5 ages, elder than 5 ages to 6 ages, elder than 6 ages to 7 ages are $29 \%, 29 \%, 31 \%$, and $11 \%$.

\section{Research Findings}

On the basis of questionnaire survey result, combing with the above interview content of family parents, we mainly find the following several points.

(1)Parents' content preference on tablet computer significantly affects children' content preference. Analysis shows that parents' content preference on tablet computer has very significant relationship with children' content preference. Parents prefer to use tablet computer to 'watch TV drama' and 'play games', then children also take on the preference of 'playing games'; parents prefer to use tablet computer to 'read' and 'handle official business', then children will prefer to 'see e-book'; parents prefer to use tablet computer for 'instant messaging', then children also prefer to use it for 'interactive chat'. As you see, in the process of the use in daily life, children are influenced by parents' behavior of using tablet computers.

(2)children' usage amount and frequency are significantly influenced by the type of parents contacting with media. Analysis shows that the more parents contact with phone and computer at home, the more children use tablet computers. There into, $\mathrm{P}$ values of mobile phones, children' usage amount and frequency are less than 0.001 , the effect is very significant. On one hand, now most parents use touch screen mobile phones whose functions are very similar with tablet computers, many children initially contact with touch-screen products starting from parents' mobile phones. On the other hand, many children regard parents as a 'primary group' in daily life, they imitate their 
behavior by observing parents' words and deeds. Likewise, the more parents read books, the more children likely to use tablet computers to see e-book are, and their usage frequency naturally decreases under the words and deeds of parents.

(3)Parents' attitude towards tablet computers affects the usage behavior of children to a certain extent. The more parents think tablet computers hinder interpersonal communication, the easier they use 'control' approach to reduce children' use are, and the restriction of parents often makes children have stronger desire to play games; on the other side, combining with the interview result, we find that when children focusing on using tablet computers, they ignore parents' some daily care (such as questioning, dressing, eating, etc.), this also increasingly deepens parents' negative impression on tablet computers in this aspect.

(4)Parents' using motivation of tablet computers affects the usage behavior of children to a certain extent. Combining with questionnaire open questions and parents interview, we analyze that if parents use tablet computers for the purpose of getting information, their children' preference for 'playing games' is more significant, it may be because this type of parents will actively look for and provide children with some 'early education' types of games suitable for children in their opinions, furthermore, their opinions on tablet computers are also slightly open and they are not so strict with managing children' behavior of playing games. In addition, if parents use tablet computers for recreational purposes, it may be because they regard tablet computers as a tool for relaxing, and they also correspondingly put less restriction on it and their children also use more.

(5)The tablet interactive relationship between parents and children affects the usage behavior of children to a certain extent. The more conflicts between parents and children on tablet computers there are, the more children use tablet computers, and the greater children' preference for playing games is. This confirms children' requirements of pursuing fantasy with avoidance put forward in Schramm research to a certain extent, children are likely to use tablet computer games to escape. Parents' 'activity participation' interactive type has a great effect on the behavior of children' 'using by sharing'. The more parents actively involved in children' tablet computer using process are, such as playing tablet computer games with children and discussing using skills, etc., the more likely they inspire children' interest in tablet computers are, and then children' behavior of sharing tablet computer using process and playing tablet computer games with others also increases.

(6)Parents mostly adopt restrictive interventional procedures with regard to children' tablet computer using.Analysis shows that in the process of children using tablet computers, nearly $70 \%$ percent of parents often take measures of 'asking for permission' and 'setting time', and $50 \%$ of parents take more measures of 'limiting content'.
On the contrary, parents who often and mostly share and discuss with children are less than $10 \%$, in this point, highly educated parents will pay more attention to help and guide children' using of tablet computers, but generally speaking, interactive means of positive intervention are still lacking. Combining with parents and children interviews, we find that parents' assistance in children' tablet computer using guidance and content selection is very insufficient, more children are to download games by themselves or directly use the existing content in parents' cell phones and computers, the influence of content quality is worth watching.

(7) 'Overtime' and 'being prejudicial to health' are the main causes of tablet computer parent-child conflict. We can know from questionnaire analysis and late feedback that about $40 \%$ - $60 \%$ of parents have conflicts with children with regard to tablet computers, even maltreatment cases occur. Although tablet computers are recognized by most parents in aspect of advantages such as getting information, the support rates of tablet computers being easy to make children 'addict', 'being prejudicial to health' and other negative views reach to $60 \%$ - $80 \%$, parents' attitude towards children using tablet computers is not very optimistic, and highly educated parents are particularly true in this point. The main causes of conflict are that, parents are extremely sensitive to children' usage time due to being worried about children' vision problems and psychological problems, and their requirements for time cannot agree on children' actual needs. Secondly, many parents have high expectations for children in 'following the rules' and 'promise keeping', but due to lack of time sense and weak behavior control ability, children are very easy to exceed time limit and cause the intervention of parents.

In general, the above conclusions all confirm that media contact behavior factors of parents have impact on media contact behavior of children in terms of using tablet computers.

\section{Strategy and Suggestion}

With the increase of age, children' self-consciousness is gradually awakened, they hope to explore more unknown things, and they want to show their power by controlling the environment, thus the operation on home media is relatively simple, which can meet the children' control demand to a certain extent. Besides, children love to imitate, thus the parents' application situation on media will also imperceptibly make effect on children, and then children will imperceptibly imitate parents' behaviors on media application. Faced with the situation that "children obtain the knowledge and skills of applying all kinds of media through the interaction with parents and all kinds of media for a long time"[2], how should the parent guide and help the preschool children to achieve the multiple objectives of cognition, communication and entertainment through 
applying the tablet computer, thus we put forward the following suggestions from the view of media literacy.

(1) Improve the parents' tablet computer application behaviors.

The attitude of parents on iPad is the important factor that children apply it, as the "basic group" during the process of preschool children socialization, the parents should make themselves as the example, strive to become the children' opinion leaders, then become the "gatekeeper" that are familiar with media, can cleverly apply the media and explain the tablet computer message to the children.Parents' tablet computer application demonstration is best to follow the principle of "infiltration". "Because this demonstration is different with the form of separate setup course in school, it is more like an implicit education, which needs to permeate into the normal life." ${ }^{\text {[3] }}$ Thus makes the tablet computer literacy education become a part of family life, finally become a kind of living way, and makes everybody get used to it. The best way and result of demonstration is to let the children form the independent and healthful application habits and critical media reading ability.

(2)Control the "TV" trend of tablet computer, improve the selection and intervention of suitable content.

It can be seen from this research result that, the majority children apply the table computer as "mini TV" to see all kinds of carton, compared with tablet computer games, this is a more noteworthy content model. Developmental Psychologist George Joses, American scholar Lisa Guernsey and other scholars find through the test that, TV is lack of the most important "Two-way information exchange" needed by children' cognition, thus its cognition effect is limited ${ }^{[4]}$. But in the interactive computer games and live demonstrations, even the children within 30 months can also learn something. Therefore, parents can consciously help children choose some games content with two way communication feature.

(3)Improve the content selection participation degree of children.

When the children' preference on specific content reflected through the selection, they can obtain the maximum pleasure and under the highest intervention level. The research proves that, the good influence of active acceptance on children' life is more than the passive acceptance. Therefore, parents can ask more advice from children, such as what they want to play, so that the children participate into the selection process of games. In the exercise of many times' content selection, the children can know more and more about how to communicate and select the game that suit for themselves, and then they can obtain more information benefit for them.

(4)Strengthen sharing, discussing and other positive intervention.

The large number of survey shows that, children, especially the children with low ages, hope their parents to accompany and provide guidance during their media applying process. ${ }^{[5]}$ Playing the tablet computer with children not only meets the children' psychological needs, but also promote children' social and emotional development by this way.

\section{Conclusion}

Just as the words said by America scholar Lisa Guernsey, we already live in the era of screen, so it is not suitable to say "you should read book inside of watching tablet computer". Since the parents' media contact behavior influence the children' media contact behavior in many aspects. Therefore, as the important "primary group" learned by children during the media communication activity, parents should only continue to be social, learn new knowledge, accept new things, can they update the concept, transform the consciousness and then adapt the changed and developed society, so as to keep up with the pace of times. In information age, if parents do not get the related "media literacy education", they do not have the ability to educate their children, parents should be the best guardian and guide for children in the information age, because parents know their children most ${ }^{[6]}$. Parents can improve their media literacy through the 3 ways of "understanding, learning and moving". As for "understanding", the first is to fully understanding children, carefully observing what media they contact and do, which are useful or risk, and then make targeted learning and guidance; "learning" is to "contact with different media to understand the content of various media" on time. "Moving" is the most important step, no matter how busy, parents should take time to learn with children, let the children feel the love and concern provided by parents. In this way, even they have problems, they will ask help from parents, while not only from media. Therefore, on the problem of media application, parents should insist on the concept of "children standard", respect all the demands of them, including contacting and applying the media. Then understand their media application is the external expression of their feelings, thoughts, demands and aspirations. ${ }^{[7]}$

\section{References}

[1] Zhang Haibo, Apple Age: Study on the Media Survival and Media Literacy Education of Children "after 00” ,Guangzhou: Southern Daily Press, pp.118,2013.

[2] Zhou Yan, Investigation on the Influence Factors of Media Contact in Children in Guangzhou , Preschool Education Research, vol.7, pp.17-24, 2009.

[3] Chen Gang, Role of Parents in children' Network Literacy Education, Journal of Shandong Youth College, vol.3, pp.16-19, 2013.

[4] Huang Dong, Whether iPad Make Children Smarter or More Stupid, Global Perspective, vol.9, pp.64-66, 2013. 
[5] Kong Xue, Research on the Children Media Literacy of Children Media Participating in the New Media Environment, Master Thesis of Nanjing University of Science and Technology, pp.52, 2014.
[6] Zhang Haibo, Media Literacy - Family's Book, Southern Daily Press, pp.38, 2013.

[7] Elvy Cohen, Unconditional Cultivating, Translated by Xiao Wu, Geng Dan. Tianjin Education Press, pp.21, 2012. 